\title{
Long-term results after carinal resection for carcinoma: Does the benefit warrant the risk?
}

\author{
Marc de Perrot, MD, Elie Fadel, MD, Olaf Mercier, MD, Sacha Mussot, MD, Alain Chapelier, MD, \\ and Philippe Dartevelle, MD
}

From the Department of Thoracic and Vascular Surgery and Heart-Lung Transplantation, Centre Chirurgical Marie-Lannelongue, Le Plessis-Robinson, France.

Read at the Eighty-fifth Annual Meeting of The American Association for Thoracic Surgery, San Francisco, Calif, April 10-13, 2005.

Received for publication April 14, 2005; revisions received July 10, 2005; accepted for publication July 19, 2005

Address for reprints: Philippe Dartevelle, MD, Department of Thoracic and Vascular Surgery and Heart-Lung Transplantation, Centre Chirurgical Marie-Lannelongue, 133 Avenue de la Resistance, 92350 Le PlessisRobinson, France.

J Thorac Cardiovasc Surg 2006;131:81-9

$0022-5223 / \$ 32.00$

Copyright () 2006 by The American Association for Thoracic Surgery

doi:10.1016/j.jtcvs.2005.07.062
Objective: We sought to determine whether the benefit warrants the risk in patients undergoing carinal resection for carcinoma.

Methods: This was a retrospective single-center study.

Results: Between June 1981 and August 2004, 119 patients underwent carinal resection for carcinoma in our institution. Carinal pneumonectomy was performed in 103 cases (96 right and 7 left pneumonectomies), carinal resection plus right upper lobectomy in 3, carinal resection after left pneumonectomy in 2, and carinal resection without pulmonary resection in 11 . Superior vena caval resection was combined with carinal pneumonectomy in 25 patients with bronchogenic carcinoma (13 patients had complete superior vena caval resection with graft interposition). Nine $(7.6 \%)$ patients died in the hospital or within 30 days of the operation. Follow-up was complete for 117 (98\%) patients up to August 2004 or to the date of death. The 5- and 10-year survivals were $44 \%$ and $25 \%$, respectively, for patients with bronchogenic carcinoma $(n=100)$. However, survival was significantly better in patients with $\mathrm{N} 0$ or $\mathrm{N} 1$ disease $(\mathrm{n}=73)$ than in those with $\mathrm{N} 2$ or N3 disease ( $\mathrm{n}=27 ; 53 \%$ vs $15 \%$ at 5 years, respectively). The 5 - and 10 -year survivals in the remaining 19 patients reached $66 \%$ and $48 \%$, respectively, and were best in patients with neuroendocrine carcinoma (100\% survival at 10 years) and adenoid cystic carcinoma (69\% survival at 10 years).

Conclusions: Surgical intervention for carcinoma involving the carina is feasible, with acceptable mortality and good long-term survival in selected patients. The presence of positive $\mathrm{N} 2$ disease should, however, be considered a potential contraindication to carinal resection in patients with bronchogenic carcinoma because of the poor long-term survival.

$\mathrm{R}$ efinement in techniques of tracheal surgery and bronchial sleeve lobectomy has made carinal resection and reconstruction possible. However, the potential for complications remains high, and few centers only have accumulated sufficient expertise to safely perform the operation. Although the risks of carinal resection and reconstruction are certainly justifiable in patients with benign and low-grade malignancies, the usefulness of carinal surgery for carcinoma involving the carina is still questionable. Few series have reported long-term survival after carinal resection for bronchogenic carcinomas or adenoid cystic carcinomas involving the carina. ${ }^{1-3}$ The objective of this article is to review our experience in carinal resection for carcinoma and to determine whether the benefit warrants the risk.

\section{Materials and Methods}

\section{Patient Data}

All patients who underwent carinal resection for carcinoma in our institution between June 1981 and August 2004 were reviewed. Patients undergoing carinal resection for benign 


$$
\begin{aligned}
& \text { Abbreviations and Acronyms } \\
& \begin{aligned}
\text { CT } & =\text { computed tomography } \\
\text { NSCLC } & =\text { non-small cell lung carcinoma } \\
\text { PTFE } & =\text { polytetrafluoroethylene } \\
\text { SVC } & =\text { superior vena cava }
\end{aligned}
\end{aligned}
$$

diseases or malignant diseases other than carcinoma were excluded from the study. Data were obtained from the hospital database, hospital charts, referring physicians, and/or from the patients or the patients' family. Follow-up was completed up to August 2004 or to the date of death. Postoperative death included all patients who died within 30 days of surgical intervention or before being discharged from the hospital. The study was approved by the institutional review board.

\section{Preoperative Investigations}

The preoperative workup has evolved over the years but currently consists of chest radiography, chest computed tomography (CT), pulmonary function testing, arterial blood gas measurement, ventilation-perfusion scanning, electrocardiography, and echocardiography. CT scanning of the upper abdomen and CT or magnetic resonance imaging of the brain are routinely performed to exclude distant metastasis. Bronchoscopy is always performed preoperatively to determine the extent of involvement and adequacy of the remaining airway. Mediastinoscopy is performed at the time of surgical intervention in patients presenting with bronchogenic carcinoma to exclude N2 disease. Bone scanning is performed in symptomatic patients or in patients with abnormal blood work. Stress thallium studies, maximum oxygen uptake, and exercise testing are used when indicated.

Pulmonary angiography is performed for carinal tumors arising from the anterior segment of the right upper lobe because invasion of the right upper lobe (mediastinal) artery usually indirectly reveals invasion of the posterior aspect of the superior vena cava (SVC). Superior cavography is performed if the SVC is potentially involved. Transesophageal echography is occasionally performed to evaluate tumor extension to the posterior mediastinum, especially the esophagus or the left atrium.

\section{Surgical Technique}

Our technique of carinal resection has been reviewed in detail elsewhere. ${ }^{4,5}$ Only some specific points are presented herein. The patient is initially intubated with an extra-long oral endotracheal tube that can be advanced into the opposite bronchus if single-lung ventilation is desired. Once the carina has been resected, the opposite main bronchus is intubated with a cross-field sterile endotracheal tube connected to a sterile tubing system. After the trachea and bronchi are anastomosed, the cross-field tube is withdrawn, and the patient is ventilated through the endotracheal tube left in place above the anstomosis.

The incision varies according to the type of carinal resection. Carinal resection without sacrifice of pulmonary parenchyma is approached through a median sternotomy. The pericardium is opened anteriorly, and the tracheobronchial bifurcation is exposed between the SVC and the ascending aorta. The exposure is facil- itated by completely mobilizing the ascending aorta and both main pulmonary arteries. The ligamentum arteriosum is systematically sectioned.

Right carinal pneumonectomy is performed through a right thoracotomy in the fifth intercostal space. After division of the azygos vein, the tracheobronchial bifurcation is mobilized. Circumferential dissection should be limited to no more than $2 \mathrm{~cm}$ from the proposed lines of transection of the lower trachea and the left main bronchus. If segmental resection of the SVC is planned, the vascular procedure is usually performed before division of the airway. The SVC is clamped proximally at the confluence of the brachiocephalic veins and distally at the cavoatrial junction and divided on each side of the tumor. Section of the SVC facilitates exposure and stapling of the right pulmonary artery in the interaortocaval groove. The SVC is reconstructed with a ringless straight 18 or $20-\mathrm{mm}$ sized polytetrafluoroethylene (PTFE) graft. The PTFE graft is protected with gauze soaked in povidone-iodine during reconstruction of the airway to prevent graft contamination.

Although left carinal pneumonectomy was performed through a left thoracotomy early on in our experience, median sternotomy is currently our preferred approach. Median sternotomy provides superb exposure to the tracheobronchial bifurcation, has less incisional discomfort, and results in less ventilatory restriction than a thoracotomy. The main disadvantages are that freeing pleuroparietal adhesions can be difficult, and mobilization of the left hilum requires cardiac retraction that might cause some hemodynamic instability.

The tracheobronchial anastomosis is always performed in an end-to-end fashion. We first apply a running 4-0 polydiaxone (PDS; Ethicon, Inc, Somerville, NJ) suture on the deepest aspect of the airway with respect to the surgeon. For instance, in a right carinal pneumonectomy this represents the left aspect of the cartilage wall of the trachea and left main bronchus. The running suture is then tied at each end with 2 independent polydiaxone sutures, the knots of which are made outside the lumen. Thereafter, several interrupted stitches of 3-0 polydiaxone or 3-0 Vicryl (Ethicon, Inc) are placed in the remaining part of the anastomosis. They are tied after all of them have been placed to correct for size discrepancies. The stitches applied on the membranous portion are tied at the end to avoid any traction and potential tears.

At the end of the procedure, the anastomosis is controlled with bronchoscopy, and secretions are cleaned up from the airways. Patients are extubated in the operating room. Pain relief is achieved with epidural analgesia or patient-controlled analgesia. A temporary tracheostomy can be performed at the end of operation to reduce the physiologic respiratory dead space and facilitate direct aspiration when the predicted residual ventilatory functional reserve is borderline or the patient's collaboration is reduced.

\section{Statistical Analysis}

All results are expressed as medians and ranges or as absolute numbers and percentages. Potential risk factors for postoperative mortality were identified by means of univariate and multivariate analysis. All variables were initially subjected to univariate analysis with the $\chi^{2}$ test to avoid overadjustment by using too many variables in the multivariate models. Factors with a $P$ value of less than .1 were then considered as risk factors in the multivariate logistic regression analysis. Survival rates were calculated by 
TABLE 1. Patient characteristics

\begin{tabular}{lr}
\hline Age (y) & 55 \\
Median & $36-73$ \\
Range & \\
Sex (n) & 99 \\
Male & 20 \\
Female & \\
Clinical presentation (n) & 44 \\
Hemoptysis & 32 \\
Weight loss & 29 \\
Dyspnea & 19 \\
Pneumonia & 18 \\
Chest pain & 5 \\
Clubbing & 3 \\
Empyema & 1 \\
HPO & 1 \\
Hiccups & \\
Diagnosis (n) & 100 \\
Non-small cell lung carcinoma & 8 \\
Adenoid cystic carcinoma & 5 \\
Neuroendocrine carcinoma & 4 \\
Mucoepidermoid carcinoma & 2 \\
Metastatic renal cell carcinoma &
\end{tabular}

HPO, Hypertrophic pneumonic osteoarthropathy.

means of life-table analysis. Kaplan-Meier curves were plotted and compared with the log-rank test. Statview V (Abacus Concept, Berkeley, Calif) software was used for all analyses.

\section{Results}

A total of 119 patients underwent carinal resection for carcinoma over the 23-year period of the study. There were 99 men and 20 women with a median age of 55 years (range, 36-73 years). The main clinical symptoms at presentation were hemoptysis $(n=44)$ and dyspnea $(n=29)$. Indications for surgical intervention were non-small cell lung carcinoma (NSCLC) in 100 patients, adenoid cystic carcinoma in 8 patients, neuroendocrine carcinoma (carcinoid tumor) in 5 patients, mucoepidermoid carcinoma in 4 patients, and metastatic renal cell carcinoma in 2 patients (Table 1). Five patients underwent preoperative rigid bronchoscopy with core-out of the tumor to open the distal airways.

A total of 23 patients underwent induction therapy with either chemotherapy $(\mathrm{n}=18)$ or chemoradiation therapy $(\mathrm{n}=5)$ with 40 to $45 \mathrm{~Gy}$ of radiation. An additional 4 patients had a history of radiation therapy before carinal resection for breast cancer $(n=2)$ or Hodgkin's disease $(\mathrm{n}=1)$ or as adjuvant therapy after a right lower lobectomy for bronchogenic carcinoma classified as pT2 N2.

Right carinal pneumonectomy was performed in 96 patients. Seven patients underwent a left carinal pneumonectomy through a left thoracotomy $(\mathrm{n}=3)$ or through a median sternotomy $(n=4)$. Two patients underwent carinal resection through a median sternotomy 3 and 4 weeks after a left pneumonectomy performed in another center. Both of these patients were referred to us because of positive microscopic bronchial margin of the left mainstem bronchial margin at the time of pneumonectomy. Three patients had carinal resection associated with a right upper lobectomy; the bronchus intermedius was reimplanted into the side of the trachea $(n=2)$ or into the side of the left mainstem bronchus $(\mathrm{n}=1)$.

A total of 11 patients had carinal resection without lung resection. The carina was usually reconstructed with an end-to-end anastomosis of the left mainstem bronchus into the trachea and an end-to-side anastomosis of the right mainstem bronchus into the trachea $(\mathrm{n}=8)$. In one patient the left mainstem bronchus was too short to reach the trachea without tension, and thus the right mainstem bronchus was anastomosed end-to-end to the trachea, and the left mainstem bronchus was anastomosed end-to-side to the bronchus intermedius. In 2 patients the carina and the right mainstem bronchus were partially resected, and the left mainstem bronchus was anastomosed end-to-side to the defect.

SVC resection was combined with a right carinal pneumonectomy in 25 patients with bronchogenic carcinoma. The SVC was completely resected en bloc with the tumor in 13 patients and was reconstructed with PTFE sized $16(\mathrm{n}=$ $1), 18(n=9)$, or $20(n=3)$. The SVC crossclamp time ranged between 15 and 45 minutes (median, 23 minutes). The remaining 12 patients had only partial resection of the SVC and did not require graft interposition. One patient had complete agenesia of the inferior vena cava and had large collaterals draining into the azygos vein. The azygos vein was anastomosed to the right atrium after being sectioned from the SVC to maintain adequate venous return from the lower part of the body. Part of the left atrium was resected in 10 patients, the muscular wall of the esophagus in 4 patients, and the chest wall ( 2 ribs) or the diaphragm in 1 patient each.

Complete resection (R0) was achieved in 112 patients. Microscopic positive resection margin (R1) was observed in 4 patients with adenoid cystic carcinoma and in 3 patients with squamous cell carcinoma. Positive resection margins were usually seen at the bronchial or tracheal resection margins when the maximal length of the airway had already been removed $(n=6)$. In one case malignant cells were seen at the resection margin of the left atrium. NSCLCs were classified as squamous cell carcinoma $(n=76)$, adenocarcinoma $(n=16)$, large cell carcinoma $(n=7)$, and sarcomatoid carcinoma $(n=1)$. The nodal status of the NSCLC was classified as pN0 in 14 patients, pN1 in 59 patients, and $\mathrm{pN} 2$ or $\mathrm{pN} 3$ in 27 patients. Tumor size ranged between 1 and $10 \mathrm{~cm}$ (median, $4.5 \mathrm{~cm}$ ). 
TABLE 2. Postoperative complications

\begin{tabular}{lrr}
\hline & $\mathbf{n}$ & $\%$ \\
\hline Cardiac & & \\
$\quad$ Arrhythmias & 12 & 10.1 \\
Myocardial infarction & 1 & 0.8 \\
$\quad$ Cardiac herniation & 1 & 0.8 \\
Respiratory & & \\
$\quad$ Pulmonary edema & 12 & 10.1 \\
Sputum retention & 11 & 9.2 \\
Pneumonia & 9 & 7.6 \\
Pulmonary emboli & 2 & 1.7 \\
Anastomotic & & \\
Dehiscence & 9 & 7.6 \\
Local necrosis & 3 & 2.5 \\
Infectious & & \\
Empyema & 6 & 0.0 \\
Mediastinitis & 1 & 0.8 \\
Wound infection & 1 & 2.5 \\
Other & & 2.5 \\
Bleeding & 3 & 1.7 \\
Recurrent nerve palsy & 3 & \\
Chylothorax & 2 & \\
\hline
\end{tabular}

Postoperative complications occurred in 56 patients (Table 2). A total of $12(10 \%)$ patients presented with anastomotic complications (9 dehiscences and 3 local necroses). All 3 patients with local necrosis were treated conservatively, and one of them had an anastomotic stenosis requiring an endotracheal stent later on. All 9 patients with a tracheal dehiscence had an empyema, and 4 (44\%) of them died while in the hospital. Two patients eventually had an anastomotic stenosis, and one required a stent insertion. A total of $12(10 \%)$ patients had some degree of pulmonary edema in the immediate postoperative period. Five (42\%) of them required reintubation, and $4(33 \%)$ died from acute respiratory distress syndrome.

The operative mortality according to the type of procedure is reported in Table 3. All deaths occurring from tracheal dehiscence or acute respiratory distress syndrome happened after right carinal pneumonectomy. One additional patient who underwent carinal resection and reconstruction had mild pulmonary edema postoperatively. The

TABLE 3. Operative mortality according to the type of carinal resection

\begin{tabular}{lrc}
\hline Procedure & $\mathbf{n}$ & Operative death \\
\hline Right carinal pneumonectomy & 96 & $8(8.3 \%)$ \\
Left carinal pneumonectomy & 7 & 0 \\
Carinal resection after left pneumonectomy & 2 & 0 \\
Carinal plus right upper lobectomy & 3 & 0 \\
Carinal resection without lung resection & 11 & $1(9 \%)$ \\
Overall & 119 & $9(7.6 \%)$ \\
\hline
\end{tabular}

TABLE 4. Risk factors for postoperative death

\begin{tabular}{|c|c|c|c|c|}
\hline \multirow[b]{2}{*}{ Risk factors } & \multirow[b]{2}{*}{$\begin{array}{c}\text { No. of } \\
\text { patients }\end{array}$} & \multirow[b]{2}{*}{$\begin{array}{l}\text { No. of } \\
\text { deaths }\end{array}$} & \multicolumn{2}{|c|}{$P$ value } \\
\hline & & & $\begin{array}{c}\text { Univariate } \\
\text { analysis }\end{array}$ & $\begin{array}{c}\text { Multivariate } \\
\text { analysis }\end{array}$ \\
\hline Bronchogenic carcinoma & & & .2 & - \\
\hline Yes & 100 & 9 & & \\
\hline No & 19 & 0 & & \\
\hline Induction therapy & & & .3 & - \\
\hline Yes & 23 & 3 & & \\
\hline No & 96 & 6 & & \\
\hline Preoperative radiation & & & .4 & - \\
\hline Yes & 9 & 0 & & \\
\hline No & 110 & 9 & & \\
\hline Sputum retention & & & .3 & - \\
\hline Yes & 11 & 0 & & \\
\hline No & 108 & 9 & & \\
\hline Right pneumonectomy & & & .5 & - \\
\hline Yes & 96 & 8 & & \\
\hline No & 23 & 1 & & \\
\hline $\begin{array}{l}\text { Superior vena cava } \\
\text { resection }\end{array}$ & & & .07 & .09 \\
\hline Yes & 25 & 4 & & \\
\hline No & 94 & 5 & & \\
\hline $\begin{array}{l}\text { Postoperative pulmonary } \\
\text { edema }\end{array}$ & & & $<.0001$ & $<.0001$ \\
\hline Yes & 12 & 6 & & \\
\hline No & 107 & 3 & & \\
\hline Anastomotic dehiscence & & & $<.0001$ & .001 \\
\hline Yes & 9 & 4 & & \\
\hline No & 110 & 5 & & \\
\hline
\end{tabular}

patient recovered rapidly and was discharged from the hospital on the 14th postoperative day but died at home on the 30th postoperative day from acute pulmonary emboli. The predominant risks of postoperative death identified by using univariate and multivariate analyses were the development of pulmonary edema and the occurrence of tracheal dehiscence in the postoperative period (Table 4). Other factors, such as preoperative radiation therapy, sputum retention, histology, or type of operation, had no significant effect on the risk of postoperative death. Although induction therapy also had no significant effect on the risk of postoperative death, there was a trend toward a higher mortality rate in patients undergoing right carinal pneumonectomy after induction therapy (operative mortality of $13 \%$ vs $6.7 \%$ in patients undergoing right carinal pneumonectomy without induction therapy, $P=.3$ ).

Follow-up was completed up to August 2004 or to the date of death for $117(98 \%)$ patients. Two patients who migrated outside of France were lost to follow-up 1 and 6 years after their operations. Thirty-eight patients had adjuvant therapy with either chemotherapy, radiation therapy, or both. Six patients had an empyema between 2 weeks and 9 


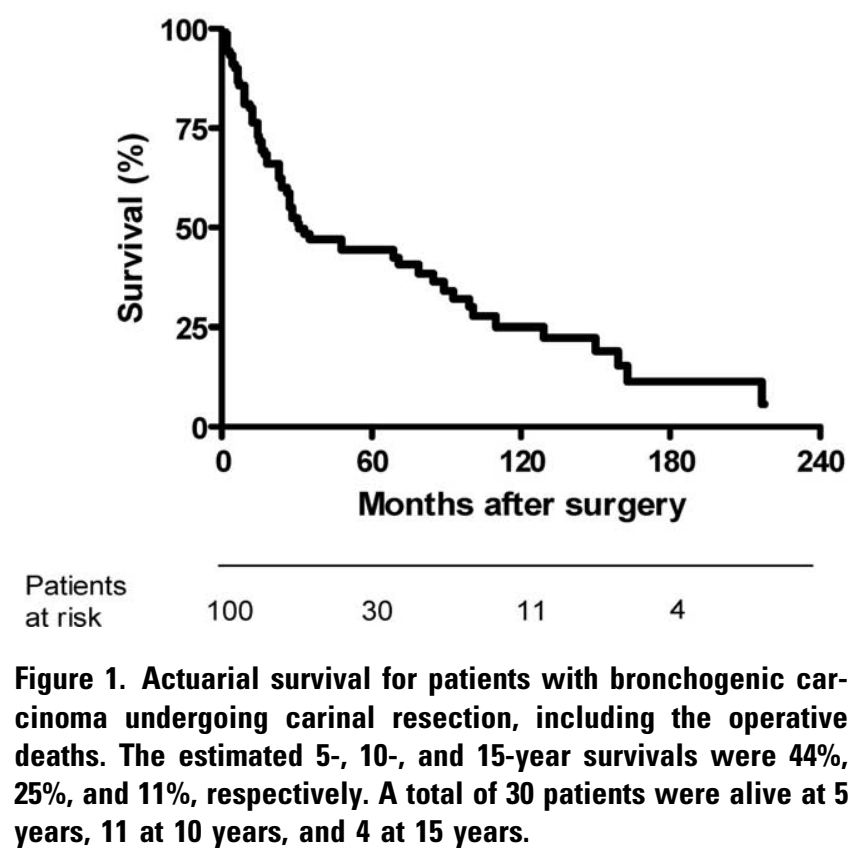

years after right carinal pneumonectomy. None of them had an anastomotic fistula, and all were successfully treated with a Clagett window.

The actuarial 5- and 10-year survivals were, respectively, $44 \%$ and $25 \%$ for patients with bronchogenic carcinoma (Figure 1). However, survival reached 53\% at 5 years in patients with $\mathrm{N} 0$ or N1 disease and was significantly better than in those with $\mathrm{N} 2$ or N3 disease (survival of $15 \%$ at 5 years; Figure 2). There was no difference in survival at 5 years between patients with $\mathrm{N} 0$ or $\mathrm{N} 1$ disease $(50 \%$ vs $55 \%$, respectively; $P=.9$ ). The actuarial 5- and 10-year survivals were $41 \%$ and $30 \%$, respectively, in patients who underwent resection of the SVC $(P=.9$ when compared with the remaining cohort of patients with bronchogenic carcinoma). Recurrences were observed at the anastomotic site in 5 patients (all of them had negative resection margins), in the mediastinum in 4 patients, and at distant sites in the remaining patients.

The actuarial 5- and 10-year survivals in the remaining 19 patients reached $66 \%$ and $48 \%$, respectively. Two patients with adenoid cystic carcinoma died 16 and 23 months after the operation, respectively, whereas the remaining 6 patients are alive 16 to 192 months after the operation (median, 26 months), leading to an actuarial 10-year survival rate of $69 \%$. All patients with neuroendocrine carcinoma are alive 25 to 126 months after the operation (median, 35 months), leading to an actuarial 10-year survival of $100 \%$. Among the 4 patients with mucoepidermoid carcinoma, 2 are alive 16 and 22 months after the operation, whereas 2 died 27 and 70 months after the operation. The

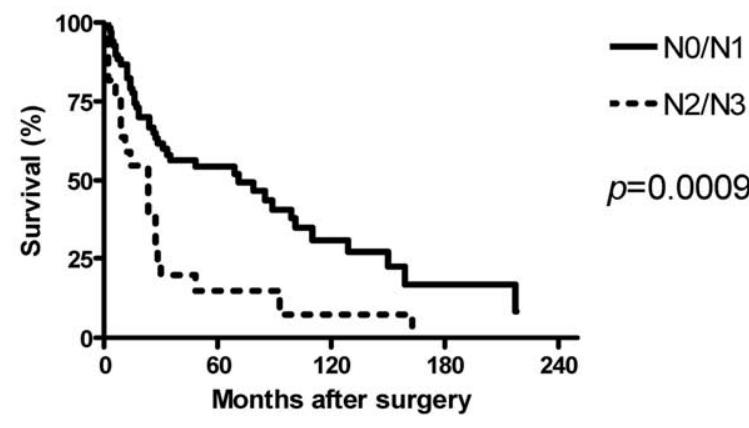

$\begin{array}{ccccc}\text { Patients at risk } & & & & \\ \text { N0/N1 } & 74 & 26 & 9 & 4 \\ \text { N2/N3 } & 26 & 4 & 2 & \end{array}$

Figure 2. The actuarial survival for patients with bronchogenic carcinoma undergoing carinal resection was significantly better in patients with pNo/N1 disease than in patients with pN2/N3 disease. The estimated 5 -year survival was $53 \%$ in patients with pN0/N1 disease versus $15 \%$ in patients with pN2/N3 disease. $P=$ .0009 , log-rank test.

2 patients with metastastic renal cell carcinoma died 22 and 23 months, respectively, after the operation.

\section{Discussion}

The optimal treatment for carcinoma involving the carina is still debated. Surgical intervention is infrequently proposed because of the complexity of the operation and the paucity of data demonstrating benefit in the long term. The results of this study demonstrate that carinal resection for carcinoma is relatively safe in experienced centers and can be associated with good long-term survival in selected patients. All patients undergoing carinal resection for neuroendocrine carcinoma are alive after 25 to 126 months, and 6 of 8 patients with adenoid cystic carcinoma are alive 16 to 192 months after the operation. In addition, 30 of the 100 patients presenting with bronchogenic carcinoma were alive at 5 years, leading to an actuarial 5-year survival of $53 \%$ if the mediastinal nodes were negative.

Our overall operative mortality of $7.6 \%$ compares favorably with that seen in other recent series. Mitchell and colleagues ${ }^{6}$ reported an operative mortality of $10 \%$ for patients operated on over the second half of their experience, and Roviaro and associates ${ }^{7}$ quoted a $4 \%$ operative mortality in their experience since 1983. These results are considerably better than those from earlier reported series and likely account for the improvement in surgical and anesthetic techniques. Careful patient selection and detailed evaluation are also important components to good surgical results. All our patients have been thoroughly assessed to determine their physiologic and pulmonary reserve before 
any carinal resection, particularly if carinal pneumonectomy was contemplated.

The surgical approach varied with the type of resection. A right thoracotomy was always performed for right carinal pneumonectomy, and a median sternotomy was usually used for carinal resection with bilateral reconstruction of the tracheobronchial tree. Left carinal pneumonectomy has been associated with more controversy as to the type of surgical approach. Bilateral thoracotomies, left thoracotomy, clamshell incision, and median sternotomy have all been reported with various success. ${ }^{3,6,8}$ In our experience we have favored median sternotomy over left thoracotomy in the past few years. We find that median sternotomy provides superb exposure to the tracheobronchial bifurcation if a large mobilization of the ascending aorta and systematic sectioning of the ligamentum arteriosum is performed. In addition, median sternotomy is associated with less incisional discomfort and results in less ventilatory restriction than a thoracotomy. The main disadvantages have been the limited access to release pleuroparietal adhesions and the hemodynamic instability observed during mobilization of the left hilum because of the cardiac retraction.

Carinal resection should always be planned without cardiopulmonary bypass. In our series 3 patients required the emergency use of cardiopulmonary bypass during the operation. Two patients had intraoperative pulmonary edema of the left lung, and cardiopulmonary bypass was started to avoid any significant tension on the suture lines during the anastomotic procedure. ${ }^{9}$ The third patient had major bleeding from the right main pulmonary artery that required the institution of cardiopulmonary bypass to be fixed. None of the remaining 116 patients required cardiopulmonary bypass to undergo carinal resection.

Nine patients died in the hospital or within 30 days of the operation. Eight of the 9 deaths occurred after right carinal pneumonectomy. These deaths were due to the development of pulmonary edema in the initial 24 to 72 hours after the operation or were the end result of an anastomotic dehiscence. The cause of postoperative pulmonary edema is unknown, but ventilator-induced trauma and excessive fluid administration during the surgical procedure are often quoted as the main risk factors..$^{1,10,11}$ Other risk factors for the development of postoperative pulmonary edema might include preoperative alcohol abuse, silent postoperative aspiration, and/or interference with lymphatic drainage. ${ }^{10,11}$ Inadequate epithelial ciliary motility of the residual lung can occur after resection of the carina, but this can usually be controlled with frequent bronchoscopy in the first few days postoperatively and did not increase the risk of postoperative death in our experience.

The development of anastomotic complications is likely due to technical factors at the time of airway resection and reconstruction. Careful dissection and precise placement of anastomotic sutures should limit tissue trauma and avoid devascularization of the anastomotic site. In addition, airway resection should be limited to a maximum of $4 \mathrm{~cm}$ at the carinal level, particularly if a right carinal pneumonectomy is performed and the left mainstem bronchus is to be reanastomosed end-to-end to the distal trachea. ${ }^{6}$ Upward mobilization of the left mainstem bronchus is limited because of the aortic arch and can easily result in excessive anastomotic tension. Dissection of the pretracheal plan is always performed to reduce the tension at the anastomotic site. However, we do not find that laryngeal or supralaryngeal release is useful to reduce the anastomotic tension at the level of the carina, and we do not routinely use a chin stitch in these patients.

Long-term survival in patients with bronchogenic carcinoma reached $53 \%$ at 5 years and $31 \%$ at 10 years if the mediastinal nodes were negative. Patients with bronchogenic carcinoma and positive mediastinal nodes, either N2 or N3, had poor survival, with a 5-year survival of only $15 \%$. Mitchell and coworkers ${ }^{1}$ reported very similar findings, with a 5-year survival of $51 \%$ in patients with NO disease and $12 \%$ in those with $\mathrm{N} 2$ or N3 disease. Hence the presence of metastastic mediastinal nodes in patients requiring carinal resection should be considered a potential contraindication. This finding underscores the importance of performing routine preoperative mediastinoscopy in these patients. We recommend performing the mediastinoscopy at the time of the planned carinal resection to avoid the development of scaring tissue along the trachea and to take advantage of the tracheal mobilization to reduce tension at the anastomotic site.

Further studies should determine the role of induction therapy in patients presenting with bronchogenic carcinoma and N2 disease. Induction therapy seems to improve survival if the mediastinal nodes can be sterilized before the lung resection. ${ }^{12}$ However, induction therapy could potentially be associated with increased operative morbidity and mortality in patients requiring right carinal pneumonectomy. Although induction therapy had no significant effect on the operative mortality in our series, it was still associated with an operative mortality that almost doubled. The operative mortality increased from $6.7 \%$ to $13 \%$ after induction therapy in patients undergoing right carinal pneumonectomy. Other authors have made similar observations and have reported an operative mortality as high as $24 \%$ after right pneumonectomy after induction therapy. ${ }^{13}$

Considering the results of recent trials on adjuvant chemotherapy for patients with completely resected NSCLC, we now recommend postoperative chemotherapy for most patients undergoing carinal resection for NSCLC, regardless of the nodal status. ${ }^{14,15}$ However, we consider adjuvant radiation therapy only in patients with positive resection 
margin, adenoid cystic carcinoma, or N2 disease and extracapsular extension.

In conclusion, this study demonstrates that carinal resection for carcinoma is relatively safe in experienced centers and can be associated with good long-term survival. Patients presenting with bronchogenic carcinoma and negative mediastinal nodes should be considered for carinal resection without any induction therapy. However, mediastinoscopy at the time of the planned operation is important because the presence of positive N2 disease should be considered a potential contraindication to carinal resection because of the poor long-term survival.

\section{References}

1. Mitchell JD, Mathisen DJ, Wright CD, Wain JC, Donahue DM, Allan JS, et al. Resection for bronchogenic carcinoma involving the carina: long-term results and effect of nodal status on outcome. $J$ Thorac Cardiovasc Surg. 2001;121:465-71.

2. Grillo HC, Gaissert HA, Grillo HC, Shadmehr MB, Wright CD, Gokhale $\mathrm{M}$, et al. Long-term survival after resection of primary adenoid cystic and squamous cell carcinoma of the trachea and carina. Ann Thorac Surg. 2004;78:1889-97.

3. Porhanov VA, Poliakov IS, Selvaschuk AP, Grechishkin AI, Sitnik $\mathrm{SD}$, Nikolaev IF, et al. Indications and results of sleeve carinal resection. Eur J Cardiothorac Surg. 2002;22:685-94.

4. Dartevelle P, Macchiarini P. Carinal resection for bronchogenic cancer. Semin Thorac Cardiovasc Surg. 1996;8:414-25.

5. Dartevelle P, Macchiarini P. Techniques of pneumonectomy. Sleeve pneumonectomy. Chest Surg Clin N Am. 1999;9:407-17, xi.

6. Mitchell JD, Mathisen DJ, Wright CD, Wain JC, Donahue DM, Moncure AC, et al. Clinical experience with carinal resection. $J$ Thorac Cardiovasc Surg. 1999;117:39-52.

7. Roviaro GC, Varoli F, Rebuffat C, Scalambra SM, Vergani C, Sibilla $\mathrm{E}$, et al. Tracheal sleeve pneumonectomy for bronchogenic carcinoma. J Thorac Cardiovasc Surg. 1994;107:13-8.

8. Maeda M, Nakamoto K, Tsubota N, Okada T, Katsura H. Operative approaches for left-sided carinoplasty. Ann Thorac Surg. 1993;56: 441-5.

9. de Perrot M, Fadel E, Musot S, de Palma A, Chapelier A, Dartevelle P. Resection of locally advanced (T4) non-small cell lung cancer with cardiopulmonary bypass. Ann Thorac Surg. 2005;79:1691-6.

10. Licker M, de Perrot M, Spiliopoulos A, Robert J, Diaper J, Chevalley $\mathrm{C}$, et al. Risk factors for acute lung injury after thoracic surgery for lung cancer. Anesth Analg. 2003;97:1558-65.

11. Deslauriers J, Aucoin A, Gregoire J. Postpneumonectomy pulmonary edema. Chest Surg Clin N Am. 1998;8:611-31, ix.

12. Betticher DC, Hsu Schmitz SF, Totsch M, Hansen E, Joss C, von Briel $\mathrm{C}$, et al. Mediastinal lymph node clearance after docetaxel-cisplatin neoadjuvant chemotherapy is prognostic of survival in patients with stage IIIA pN2 non-small-cell lung cancer: a multicenter phase II trial. J Clin Oncol. 2003;21:1752-9.

13. Martin J, Ginsberg RJ, Abolhoda A, Bains MS, Downey RJ, Korst RJ, et al. Morbidity and mortality after neoadjuvant therapy for lung cancer: the risks of right pneumonectomy. Ann Thorac Surg. 2001;72: 1149-54.

14. Arriagada R, Bergman B, Dunant A, Le Chevalier T, Pignon JP, Vansteenkiste $\mathrm{J}$, et al. Cisplatin-based adjuvant chemotherapy in patients with completely resected non-small-cell lung cancer. $N$ Engl J Med. 2004;350:351-60.

15. Winton T, Livingston R, Johnson D, Rigas J, Johnston M, Butts C, et al. Vinorelbine plus cisplatin vs. observation in resected non-small-cell lung cancer. $N$ Engl J Med. 2005;352:2589-97.

\section{Discussion}

Dr Douglas Mathisen (Boston, Mass). This presentation is another example of what we have come to expect from Dr Dartevelle and his colleagues at Marie Lannelongue in Paris-outstanding results in a very difficult group of patients.

It was not that many years ago that the risk of operative mortality equaled the chance for survival, calling into question whether this was truly a valid operation. To see results of overall survival of almost $44 \%$ and an operative mortality of $7.6 \%$ puts this operation really in the realm of a standard pneumonectomy. Lest we be deceived, however, to think that these are simple operations and not challenging, one must remember, as is pointed out in the article, that these patients require very careful evaluation, strict attention to technical detail in the operating room, a keen understanding of the limits of resection and reconstruction, and dedicated postoperative care to achieve these kinds of results.

It is interesting to me how very similar our results are to yours. Operative mortality is the one area in which we look to your results as really the gold standard. An operative mortality of $7.6 \%$ is truly remarkable. Ours now in the last half of our experience has been less than $10 \%$, but long-term survival between $40 \%$ and $45 \%$, the type of complications that you saw, the type of problems that led to mortality (very similar), and the emphasis on the very poor outlook conferred when you have positive mediastinal nodes were very similar to our findings as well.

I have 4 questions. The first is a technical question. In your article you do not mention whether the anastomosis is covered with any type of local flap. I wonder whether you would just comment about some of the technical aspects of carinal resection through a median sternotomy. You have used that more liberally than we have, and I think it would be important for the audience to hear some of the technical points that you think are important when using that approach.

Dr de Perrot. With regard to the anastomosis, we cover it with either part of the pleura that is left or the pericardium or even the azygos vein after its division.

With regard to the carinal resection with a left pneumonectomy, this is certainly a very challenging group of patients, and over the past few years, most of the patients were operated on through a median sternotomy, and the exposure of the tracheobronchial bifurcation was fairly good. After freeing the ascending aorta and cutting the arterial ligament, you can expose the tracheobronchial tree relatively well. The difficulty comes when you have to dissect the pulmonary veins and when you have to retract the heart, and if you have to dissect some adhesions within the left pleural chest, that is where the difficulty comes from. But because of the good exposure of the tracheobronchial tree, that was the preferred approach over the past few years. But it is certainly still a very challenging group of patients.

Dr Mathisen. In the article you mentioned 4 deaths from acute respiratory distress syndrome. We have seen this as well. Have you changed your intraoperative management or postoperative care to address that issue? We have become more and more convinced that the predominant factor is barotrauma during the operation. Do you have any thoughts about whether you have changed your management intraoperatively or postoperatively?

Dr de Perrot. We have not directly changed our management. These 4 deaths were over a relatively long period as well. But 
certainly we have seen occasionally some degree of pulmonary edema. Often it resolves after a few days. Some patients require noninvasive ventilation. If it is not too severe, it just resolves, but there is no significant factor where we have been able to determine who is at risk of having pulmonary edema postoperatively, and certainly we try to avoid damage to the left lung during the operation with nontraumatic ventilation, and we also try to keep these patients as dry as possible, as you would do for a pneumonectomy.

The other things we have seen that I did not show is this: if you look at the right pneumonectomy, in that group of patients, those who did not have induction therapy had an operative mortality of about $7 \%$, whereas those who had induction therapy with or without radiation but with chemotherapy had an operative mortality of $13 \%$. Therefore that certainly is increasing the risk of postoperative complications, although it does not show up with significant results in the data.

Dr Mathisen. The second issue about operative mortality relates to anastomotic problems. I think there were 12 anastomotic problems that led to 4 deaths. Have you analyzed further in detail what was responsible for the anastomotic problems? Was it purely a function of extent of resection, or could it have been other factors, such as preoperative therapy, mediastinoscopy, or type of resection?

Dr de Perrot. There was no factor that came out. Certainly the length of the resection was a risk factor. You very well have shown in your data that you can resect up to $4 \mathrm{~cm}$, and already between 2 and $4 \mathrm{~cm}$ you are increasing the risk. Most of the patients had a resection of about 2 to $3 \mathrm{~cm}$, and very few had more than $3 \mathrm{~cm}$. That is the only factor that could come into play, but there were no factors in these 4 patients that I could really determine from this analysis.

Dr Mathisen. Were there any patients in this group, of the ones who had anastomotic problems, who died beyond 30 days as a result of their anastomotic problem?

Dr de Perrot. There were some, yes. Most of these patients have been in the hospital for a prolonged period of time. Even those who survived were in the hospital for a prolonged period of time, and even though they did not die from the anastomotic complication, it certainly increases their likelihood of having complications later on down the road, even several months after the operation. Therefore for these 4 deaths, I do not know quite exactly when the deaths were, but certainly some of them were beyond 30 days, yes.

Dr Mathisen. Finally, I was particularly struck by the number of patients who had superior vena cava (SVC) involvement and equally struck by the good results, survival of, I think, 25 patients, nearly a $40 \%$ survival in this group of patients. I wonder whether you could comment on the role of adjuvant therapy in that group and then just a final comment about the adjuvant therapy in this group at large. I think there was a total of 38 patients who received some type of adjuvant therapy after carinal resection.

Dr de Perrot. Twenty-five patients had resection of the SVC, and 13 of them had frank invasion of the SVC and required an interposition graft. The number has increased progressively over the years, and most of these patients were operated on over the past 10 years; therefore it is with increasing experience that the number of patients has increased. Related to the outcome, there are too few patients really to look at the outcome precisely in that group of patients. Overall, the outcome was relatively similar to that of the patients who had only carinal resection. But this group at large will benefit from adjuvant therapy, and only $38 \%$ of this cohort of patients had adjuvant therapy because the data were not supporting adjuvant therapy at that time, except for N2 disease. Now we have better data proving that adjuvant therapy works for early-stage lung cancer. Certainly all of these patients should have at least chemotherapy postoperatively.

Dr Mathisen. Once again, congratulations on a very outstanding report. Thank you.

Dr Alec Patterson (St Louis, Mo). Marc, I would just like to make a comment and ask you a question. You mentioned the difficulty of exposing the left hilum through an anterior approach. In the last year or so, we have been using an anterior approach for a variety of things, much more commonly than before, and also in our transplantation experience, which more or less demands an anterior approach. We found that the cardiac Octopus suction stabilizer can be very helpful. With this device applied to the apex of the heart, you can lift the heart vertically out of the mediastinum, put it wherever you want without compromising hemodynamics, and get a beautiful exposure of the left hilum.

You must have an incidence of postpneumonectomy pulmonary edema, particularly in the right carinal pneumonectomy experience. Do you have a specific protocol for the management of those patients?

Dr de Perrot. Postoperatively?

Dr Patterson. Yes, for patients who experience postresection or postpneumonectomy pulmonary edema.

Dr de Perrot. Well, the protocol is really the same as for any patient with pulmonary edema. The treatment would be to try to keep them as dry as possible, as long as their kidney function tolerates. We have a tendency to use bronchoscopy for these patients very frequently as well. Several of these patients have sputum retention and cannot cough up very well. Part of it is the pain, and the other problem is that the clearance of the secretions is not as good because of the anastomosis. Therefore a large group of these patients will have a bronchoscopy almost every day really to help them clear up the secretions. Therefore that would be another part of the protocol. Otherwise, noninvasive ventilation is useful, and we try to do everything we can to avoid having to reintubate them unless it is really necessary. The last thing is that in some of these patients, if they are not collaborating well enough, tracheostomy can be a useful tool to help them come through the postoperative period, and then you can just remove the tracheostomy before they leave the hospital. It is really a useful tool to use early on rather than later on in these patients, I think.

F. Griffith Pearson (Mansfield, Ontario, Canada). Dr de Perrot, I thoroughly enjoyed that clear presentation of quite a great article, and I will take the opportunity to congratulate Dr Dartevelle on again bringing an area of controversial and difficult surgical intervention into perspective and encouraging the rest of us to be more optimistic and also to pay attention to the details that are really quite original in many of his prior presentations and this one.

I was at a meeting in Treviso, and it was 5 or 6 years ago, maybe more, when Dr Dartevelle presented, I think, 55 cases of carinal resection, and there was one technical feature in the indi- 
cations for carinal resection that I thought might be important to clarify. If I remember correctly, something like $30 \%$ or $40 \%$ of the patients had a lesion on the right side, or maybe it was on the left, but on the right side that was within a centimeter of the carina but not necessarily involving the carina. I can only say that in the past I have assumed I was not going to do a carinal resection if I could divide the airway obliquely and end up with a resection margin that was histologically free. Therefore I have always wondered whether some of the patients in that series might have been manageable by our older standards, by a right pneumonectomy, and whether that would influence survival. Whether it would influence survival, nobody can know. But I would like to hear a response to that. Whether you have had that question asked and can answer it, I am not sure, but I would appreciate clarification on that issue.

It was a great paper.

Dr de Perrot. Thank you, Dr Pearson.

That is certainly something I was looking at when I was reviewing the chart. It is something that I was paying attention to. It is difficult to retrieve the information from the chart in an operation like that, but that is an area that I was looking at because one of the concerns when you have a very short stump on the right side is that you put too much tension on your closure.

That is one of the risk factors for bronchopleural fistula. But certainly, from what I could see in the chart, most of these tumors were very close to the trachea. The majority of these patients had positive microscopic bronchial margins that were within $1 \mathrm{~cm}$ of the carina. Therefore it is not necessarily patients who had invasion of the carina by the tumor that could be seen at the time of the bronchoscopy, but certainly a large group of them had a positive bronchial margin. It is very judgmental to determine whether you can safely close a stump or whether you have to do a carinal resection to do a safe procedure. Therefore I could not really retrieve from the chart, but certainly all these tumors were within $1 \mathrm{~cm}$ of the carina, I would say.

Dr W. Roy Smythe (Temple, Tex). I enjoyed your presentation. It is a great series.

I just have one question about the fact that most of the dehiscences were after right carinal pneumonectomies, and with your inability to do a hilar release on the left side, do you routinely do a laryngeal release on those patients now? Has that altered your practice at all?

Dr de Perrot. For the right pneumonectomy, these patients did not need any hilar release. Those who needed a release were the patients who had a carinal resection with a right upper lobectomy. Of the 3 , one had a hilar release, and one had a laryngeal release. But in general none of these patients needed a release, and certainly the laryngeal release would not have been very useful for the carina, and therefore the release would have been a pericardial opening around the pulmonary vein.

\section{ON THE MOVE?}

Don't miss a single issue of the journal! To ensure prompt service when you change your address, please photocopy and complete the form below.

Please send your change of address notification at least six weeks before your move to ensure continued service. We regret we cannot guarantee replacement of issues missed due to late notification.

\section{JOURNAL TITLE:}

Fill in the title of the journal here.

OLD ADDRESS:

Affix the address label from a recent issue of the journal here.
NEW ADDRESS:

Clearly print your new address here.

Name

Address

City/State/ZIP
COPY AND MAIL THIS FORM TO:

Mosby

Subscription Customer Service

6277 Sea Harbor Dr

Orlando, FL 32887
OR FAX TO:

407-363-9661

N/M Mosby
OR PHONE:

800-654-2452

Outside the U.S., call

407-345-4000 